\title{
artigo
}

Sousa, T.J.; Soares, T.M.; Rosario, C.R.; Rosa, D.O.S.; David, R.A.R.; Brito, H.E.S.;

Aspectos da masculinidade como impeditivo do autocuidado na saúde do homem

\section{Aspectos da masculinidade como impeditivo do autocuidado na saúde do homem}

Aspects of male as an impeditive of selfcare in human health

Aspectos del hombre como impeditivo del cuidado personal en la salud del hombre

\section{RESUMO}

Objetivo: Descrever de que forma a masculinidade interfere no processo do autocuidado à saúde do homem e discutir como a assistência de enfermagem interfere nesse processo. Método: Revisão integrativa da literatura. A coleta foi realizada entre novembro e dezembro de 2020 na plataforma Biblioteca Virtual em Saúde (BVS), onde as bases de dados estão indexadas, como: Scientific Electronic Library Online, Literatura Latino-Americana e do Caribe em Ciências da Saúde e e Banco de Dados em Enfermagem, por meio de descritores combinados três a três entre si. Resultados: Foram utilizados 10 artigos para compor a amostra. Os estudos apontam que o homem dentro de um contexto sociocultural e histórico se restringe a busca da própria saúde. Conclusão: É necessário o fortalecimento do ensino técnico científico nas academias quanto a saúde do homem, para a preparação dos futuros profissionais, dos gestores em fazer com que a política voltada para o público masculino seja implantada.

DESCRITORES: Masculinidade; Saúde do Homem; Gênero; Cuidados de Enfermagem.

\section{ABSTRACT}

Objective: To describe how masculinity interferes in the process of self-care for men's health and discuss how nursing care interferes in this process. Method: Integrative literature review. The collection was carried out between November and December 2020 on the Virtual Health Library (VHL) platform, where the databases are indexed, such as: Scientific Electronic Library Online, Latin American and Caribbean Literature in Health Sciences and and Database in Nursing, through descriptors combined three to three among themselves. Results: 10 articles were used to compose the sample. Studies show that men within a socio-cultural and historical context are restricted to the pursuit of their own health. Conclusion: It is necessary to strengthen scientific technical education in academies regarding men's health, for the preparation of future professionals, for managers to implement the policy aimed at the male audience.

DESCRIPTORS: Masculinity; Men's Health; Genre; Nursing care.

\section{RESUMEN}

Objetivo: Describir cómo la masculinidad interfiere en el proceso de autocuidado para la salud del hombre y discutir cómo el cuidado de enfermería interfiere en este proceso. Método: Revisión integrativa de la literatura. La recolección se realizó entre noviembre y diciembre de 2020 en la plataforma Biblioteca Virtual en Salud (BVS), donde se indexan las bases de datos, tales como: Biblioteca Electrónica Científica en Línea, Literatura Latinoamericana y del Caribe en Ciencias de la Salud y Base de Datos. en Enfermería, a través de descriptores se combinaron tres a tres entre sí. Resultados: se utilizaron 10 artículos para componer la muestra. Los estudios muestran que los hombres dentro de un contexto sociocultural e histórico están restringidos a la búsqueda de su propia salud. Conclusión: Es necesario fortalecer la formación científico-técnica en las academias en materia de salud masculina, para la preparación de los futuros profesionales, para que los gerentes implementen la política dirigida a la audiencia masculina.

DESCRIPTORES: Masculinidad; Salud del Hombre; Identidad de Género; Atención de Enfermería.

RECEBIDO EM: 30/12/2021 APROVADO EM: 18/02/2021

\section{Tamires Jesus Sousa}

Mestranda pela Universidade Federal da Bahia.

ORCID: 0000-0003-4141-9097

\section{Tatiane Melo Soares}

Pesquisadora independente.

ORCID: 0000-0002-0397- 5343 


\section{Clivesson Rodrigues do Rosario}

Membro do Grupo de Estudos Sobre o Cuidado em Saúde da Universidade Federal da Bahia. ORCID: 0000-0003-0061-4320

\section{Darci de Oliveira Santa Rosa}

Docente da Universidade Federal da Bahia.

ORCID: 0000-0002-5651-2916

\section{Rose Ana Rios David}

Docente da Universidade Federal da Bahia.

ORCID: 0000-0003-1316-2394

\section{Helen do Espírito Santo de Brito}

Membro do Núcleo de Pesquisa Interfaces em Saúde da Universidade do Estado da Bahia. ORCID: 0000-0002-4987-4425

\section{INTRODUÇÃO}

A ideologia cultural da masculinidade estabeleceu influência nos ideais dos homens, especialmente aqueles que se empenharam no processo de civilização em séculos passados e que tentaram construir o sentido de virilidade a partir da ideia de força, potência e autoridade. $\mathrm{O}$ que culminou em um modelo de homem, exigido por tal cultura ${ }^{1}$.

A constituição do homem com base no patriarcalismo, trouxe para esse sujeito uma série de adjetivos agregando-o diversas responsabilidades. $\mathrm{O}$ indivíduo desde muito cedo, era enquadrado numa situação onde o mesmo não tinha outras alternativas a não ser, acatar o que lhe era imposto. $\mathrm{O}$ homem não chora, não demonstra sentimentos, não é mulher, não é covarde, não é fraco, não é perdedor, o colocava em uma posição de um "super-herói". Dessa forma, ele se sujeitava a viver com base em preceitos sociais prévios e a perpetuar tudo o que lhe foi atribuído ${ }^{2}$.

É merecido dá ênfase as teorizações de gênero que só passaram a incluir os estudos sobre as masculinidades, a partir de 1980 e 1990, representando um momento crucial para que fosse dada visibilidade a todas as vertentes que destoava do homem hegemônico e isso fez com que houvesse a compreensão de que o gênero deveria ser tratado como uma categoria relacional. Tal perspectiva permitiu desconstruir a ideia "do homem universal, naturalmente viril, competitivo e violento 3 .
Percebe-se que as noções de masculinidade e feminilidade, tem sido um marcador, para que o homem se posicione efetivamente, contra tudo aquilo que o mesmo considera como do mundo feminino. Essa identificação do que lhe é pertencente ou não, gera um hiato entre o homem e o seu bem-estar biopsicossocioespiritual ${ }^{1}$.

Devido a essa construção, o ser homem passou a entender que certos assuntos não eram pertinentes a ele e sim a mulher. Por motivo de representações culturais, o gênero masculino é frequentemente associado ao não cuidado de si. A partir daí, isso pode ser explicado pelo fato de que homens geralmente respondem a um ideal de masculinidade que se reflete na não valorização de sua saúde. Com essa atitude, ele faz valer todos aqueles atributos rotulados a elé2.

No atual cenário brasileiro o cuidado à saúde da população masculina, se caracteriza pela presença limitada dos homens nos serviços de saúde, sendo identificados como fatores que potencializam tal afastamento: a pressa, a objetividade, o medo e a resistência, além das dificuldades dos serviços no acolhimento desta população ${ }^{4}$.

De acordo com estudos realizados por Oliveira et al. ${ }^{5}$, os homens procuram mais o serviço de saúde diante de alguma enfermidade, aguda ou crônica, bem como aqueles mais idosos, que se encontram em uma fase da vida onde a saúde tende a se debilitar.

Nesse sentido, motivados pela importância da desconstrução do homem, inalcançável pelas lagrimas, dor e pela ex- pressão de sentimentos, marcas estas adquiridas no processo de conjuntura de sua masculinidade, o estudo foi desenvolvido, buscando responder à questão de pesquisa: De que forma a masculinidade interfere no autocuidado na saúde do homem?

Para responder a esse questionamento, foi determinado como objetivo: Descrever de que forma a masculinidade interfere no processo do autocuidado à saúde do homem e discutir como a assistência de enfermagem interfere nesse processo.

\section{MÉTODO}

Trata-se de uma revisão integrativa da literatura, de natureza qualitativa, buscando compreender a temática em questão. Segundo Prodanov e Freitas6 o passo metodológico tem o propósito de reunir, compreender e avaliar métodos disponíveis em estudos científicos com informações amplas sobre a pesquisa, formulando uma rede de conhecimento, permitindo a síntese de resultados obtidos através de pesquisas relevantes.

O estudo foi realizado conforme as seis etapas preconizadas para sua realização, sendo elas: Identificação do tema e seleção da questão de pesquisa; estabelecimento de critérios de inclusão e exclusão para seleção dos materiais científicos; categorização dos estudos; avaliação dos estudos incluídos; interpretação dos resultados e apresentação da síntese do conhecimento, conforme preconizado pelo Revised Standards for Quality Improvement Reporting Excellence (SQUIRE 2.0) ${ }^{7}$. 


\section{artigo}

Para a construção da pergunta de pesquisa, utilizou-se a estratégia PICO que representa um acrônimo para Paciente (P), Intervenção (I), Comparação (C) e "Outcomes" (O) desfecho- pergunta orientadora do estudo. Assim, seguindo esta estrutura, formulou-se a seguinte questão de pesquisa: De que forma a masculinidade interfere no autocuidado na saúde do homem?

Realizado o levantamento entre novembro e dezembro de 2020 utilizando a plataforma Biblioteca Virtual em Saúde (BVS) onde as bases de dados estão indexadas, como: Scientific Electronic Library Online (SciELO), Literatura Latino-Americana e do Caribe em Ciências da Saúde (LILACS) e Banco de Dados em Enfermagem (BDENF), por meio dos descritores: "Masculinidade"; "Saúde do Homem"; "Gênero"; "Cuidados de Enfermagem", combinados pelo uso do operador booleano "AND".

Realizou-se o cruzamento dos descritores, combinados três a três entre si, de forma a tornar a elaboração da pesquisa clara e estruturada mantendo a qualidade e a confiabilidade da mesma, compondo uma amostra final por meio dos critérios de inclusão e exclusão, estes definidos de maneira criteriosa.

Como critérios de inclusão para seleção dos estudos foram definidos: estudo tipo artigo; publicados na língua portuguesa; disponíveis na íntegra, gratuitos e estudos que atenderam à delimitação temporal do período de 2009 a 2020, devido ao marco da Política Nacional de Atenção Integral à Saúde do Homem (PNAISH), em 2009.

Sendo assim, caracterizou-se como critérios de exclusão artigos em que os aspectos na masculinidade como impeditivos no autocuidado na saúde do homem não estivessem relacionados ao objeto de estudo, literaturas cinzentas, artigos não disponíveis gratuitamente, artigos duplicados, em outros idiomas que não seja português e artigos anteriores ao ano de 2009.

A triagem inicial dos estudos foi realizada por dois revisores de forma independente e logo após, foram realizadas comparações no tocante às etapas desenvolvidas, evidenciando, assim, divergências na seleção dos estudos e posterior consenso em relação aos materiais selecionados.

Durante aplicação dos critérios de pré-seleção, foram excluídos 8 por literaturas cinzentas, 15 duplicados e 2007 por filtros restando 221 estudos. Estes, foram submetidos a leitura dos títulos e resumos, constatando-se que 188 não tinham relação com o objeto de estudo. Os 18 artigos restantes foram submetidos a leitura na integra, dos quais 8 não deixavam claro os aspectos da masculinidade como impeditivo do auto-

Quadro 1 - Estratégia PICO

\begin{tabular}{|c|c|c|}
\hline ACRÔNIMO & DEFINIÇão & APLICAÇÃo \\
\hline$P$ & População & Homem \\
\hline I & Intervenção & Autocuidado \\
\hline C & Comparação & Impecilios no autocuidado \\
\hline O & Desfecho & Saúde do homem \\
\hline
\end{tabular}

cuidado na saúde do homem. Restando 10 que foram selecionados para a revisão. O processo de identificação e seleção dos estudos seguiu as recomendações metodológicas do Preferred Reporting Items for Systematic Reviews and Meta (PRISMA) Flow Diagram específica para revisões sistemáticas, mas que tem sido útil para outros tipos de revisões ${ }^{8-9}$ (Quadro 2).

Os materiais componentes do corpus analítico foram submetidos a um checklist criado pelos pesquisadores com vistas a extração de informações como Autores e ano, periódico, título do artigo, objetivo, método de pesquisa, resultados e público estudado.

\section{RESULTADOS}

A partir dos resultados encontrados e a análise dos artigos selecionados, o quadro 3 apresenta a caracterização dos artigos utilizados considerando a identificação dos autores, ano de publicação, título dos artigos e objetivo dos mesmos, totalizando um quantitativo de 10 artigos.

Foi aplicada a técnica de análise de conteúdo temática, que é constituída de duas etapas: pré-análise e análise. $\mathrm{Na}$ primeira etapa foi efetuada a leitura flutuante dos textos, em que se constituiu as informações, seguindo com leitura exaustiva. Essa análise tem como finalidade a compreensão geral do texto e permite organizar as informações de modo que sejam compreendidas conforme a necessidade de priorização, concedendo a construção das categorias de acordo a abrangência e transversalização entre o discorrido pelos autores dos artigos que compuseram a amostra final ${ }^{10-11}$.

Quadro 2 - Cruzamento dos descritores na BVS. Salvador, Bahia, Brasil, 2018.

\begin{tabular}{|c|c|c|}
\hline DESCRITORES & ARTIGOS ENCONTRADOS & ARTIGOS SELECIONADOS \\
\hline Masculinidade and Saúde do Homem and Gênero & 311 & 02 \\
\hline Masculinidade and Saúde do Homem and Cuidados de Enfermagem & 27 & 02 \\
\hline Masculinidade and Gênero and Cuidados de Enfermagem & 20 & 01 \\
\hline Gênero and Cuidados de Enfermagem and Saúde do Homem & 1870 & 10 \\
\hline TOTAL & 2.228 & \\
\hline Fonte: Elaborada pelos próprios autores.
\end{tabular}


Figura 1. Fluxograma de apresentação do processo inclusão e exclusão dos estudos, PRISMA. Salvador, BA, Brasil, 2020

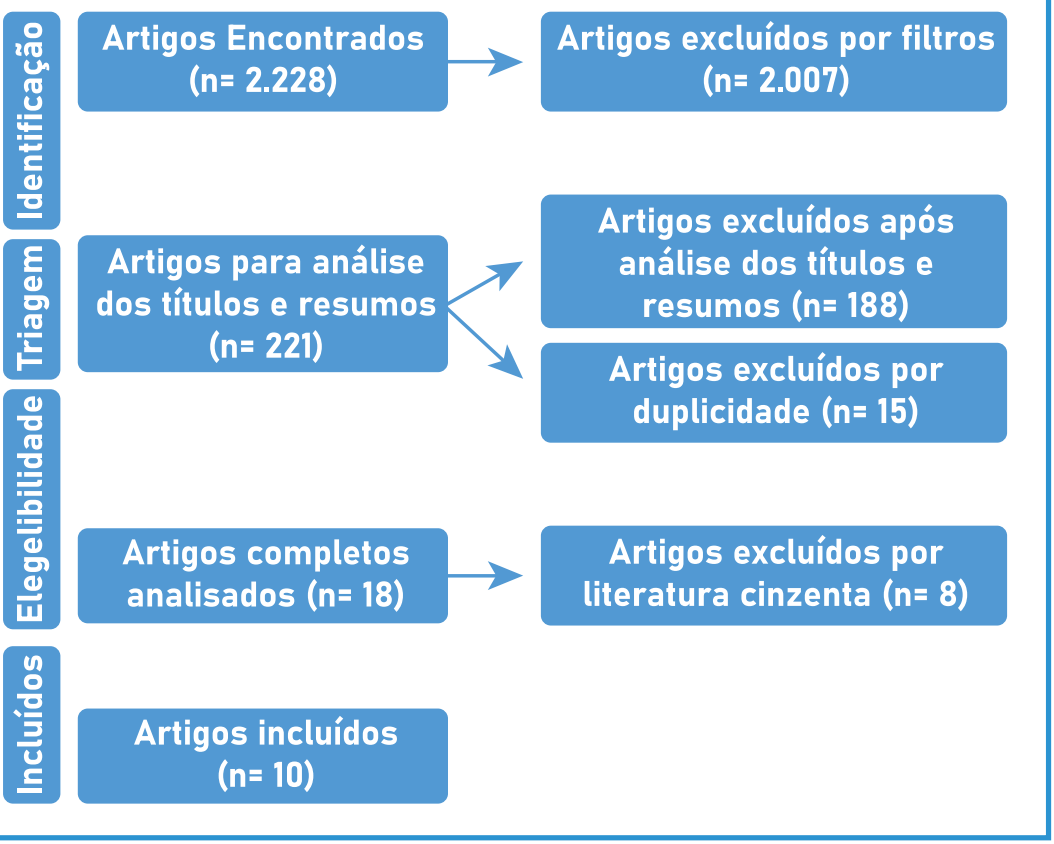

\section{DISCUSSÃO}

É perceptível que a construção da masculinidade interfere diretamente em condutas que coloca o homem em risco, expondo-o à situação de vulnerabilidade, doença e até morte. Exposições que poderiam ser evitadas caso a formação desse ser másculo, o permitisse expressar suas dores, fragilidades e envaidasse não somente no autocuidado viril do ser homem, mas também no autocuidado gerenciador da saúde como um todo, pois o olhar cuidadoso sobre si, enriquece aspectos inalcançáveis pela doença ${ }^{19}$.

Diante da leitura dos artigos selecionados visando contemplar o objetivo da pesquisa, foram construídas 03 categorias temáticas: Feições construtivas da masculinidade, fatores impeditivos para a desconstrução da masculinidade em benefício do autocuidado e assistência de enfermagem na saúde do homem. Aos quais serão discutidos a seguir:

Quadro 3 - Epítome dos artigos selecionados $(n=10)$ quanto aos autores/ano, periódico, título e objetivo. Salvador. Bahia, Brasil, 2020.

\begin{tabular}{|c|c|c|c|c|}
\hline $\begin{array}{l}\text { AUTORES/ANO/ } \\
\text { PERIÓDICO }\end{array}$ & TÍTULO & OBJETIVO & $\begin{array}{l}\text { MÉTODO DE PESQUISA/ } \\
\text { PÚBLICO ESTUDADO }\end{array}$ & RESULTADOS \\
\hline $\begin{array}{l}\text { CORDEIRO et } \\
\text { al, 2014. Escola } \\
\text { Anna Nery Revis- } \\
\text { ta de Enferma- } \\
\text { gem }\end{array}$ & $\begin{array}{l}\text { Atenção básica à } \\
\text { saúde mascu- } \\
\text { lina: possibili- } \\
\text { dades e limites } \\
\text { no atendimento } \\
\text { noturno }{ }^{12}\end{array}$ & $\begin{array}{c}\text { Analisar as contribui- } \\
\text { ções advindas com a } \\
\text { ampliação do horário } \\
\text { de funcionamento das } \\
\text { Unidades Básicas de } \\
\text { Saúde, para o horário } \\
\text { noturno. }\end{array}$ & $\begin{array}{l}\text { Estudo exploratório, com abor- } \\
\text { dagem qualitativa, realizado com } \\
\text { oito enfermeiros atuantes em } \\
\text { Unidades Básicas de Saúde que } \\
\text { possuem atendimento noturno } \\
\text { no Município de João Pessoa/PB. } \\
\text { A coleta de dados foi realizada } \\
\text { por meio de entrevista semies- } \\
\text { truturada e as falas submetidas } \\
\text { à análise de conteúdo. Público } \\
\text { estudado: Homem }\end{array}$ & $\begin{array}{l}\text { Emergiram quatro categorias: } \\
\text { Estratégias adotadas para ampliar } \\
\text { o atendimento nas Unidades } \\
\text { Básicas de Saúde; Quantitativo de } \\
\text { atendimento noturno da população } \\
\text { masculina; Campos de atendimen- } \\
\text { to as demandas de saúde mascu- } \\
\text { lina; Dificuldades vivenciadas no } \\
\text { atendimento noturno. }\end{array}$ \\
\hline $\begin{array}{c}\text { MOREIRA, } \\
\text { FONTES, } \\
\text { BARBOZA, } 2014 . \\
\text { Escola Anna } \\
\text { Nery Revista de } \\
\text { Enfermagem }\end{array}$ & $\begin{array}{l}\text { Dificuldades } \\
\text { de inserção } \\
\text { do homem na } \\
\text { atenção básica a } \\
\text { saúde: a fala dos } \\
\text { enfermeiros }^{13}\end{array}$ & $\begin{array}{l}\text { Conhecer as } \\
\text { dificuldades } \\
\text { enfrentadas pelos } \\
\text { enfermeiros no } \\
\text { contexto da saúde do } \\
\text { homem na atenção } \\
\text { básica no Município de } \\
\text { João Pessoa - PB. }\end{array}$ & $\begin{array}{l}\text { Trata-se de uma pesquisa } \\
\text { exploratória-descritiva com } \\
\text { abordagem qualitativa e a } \\
\text { análise de conteúdo. Foram } \\
\text { entrevistados } 28 \text { enfermeiros } \\
\text { que desenvolviam ações de } \\
\text { saúde há pelo menos um ano. } \\
\text { Público estudado: Homem }\end{array}$ & $\begin{array}{l}\text { Os achados revelam que } \\
\text { as dificuldades vivenciadas } \\
\text { pelos enfermeiros envolvem } \\
\text { principalmente: Ausência do } \\
\text { homem; déficit de comportamento } \\
\text { de autocuidado; sentimentos de } \\
\text { temor vinculado ao trabalho; déficit } \\
\text { na capacitação dos profissionais } \\
\text { em saúde do homem e no } \\
\text { conhecimento sobre a Política } \\
\text { Nacional de Atenção Integral } \\
\text { à saúde do Homem (PNAISH); } \\
\text { feminilização desses serviços e } \\
\text { incompatibilidade de horários. }\end{array}$ \\
\hline
\end{tabular}




\section{artigo}

Sousa, T.J.; Soares, T.M.; Rosario, C.R.; Rosa, D.O.S.; David, R.A.R.; Brito, H.E.S.

Aspectos da masculinidade como impeditivo do autocuidado na saúde do homem

\begin{tabular}{|c|c|c|c|c|}
\hline $\begin{array}{l}\text { BRITO, SAN- } \\
\text { TOS, 2013. Rev. } \\
\text { Enferm. UERJ }\end{array}$ & $\begin{array}{c}\text { Entraves para a } \\
\text { implementação } \\
\text { de programas } \\
\text { assistenciais } \\
\text { dirigidos ao } \\
\text { público mas- } \\
\text { culino: visão de } \\
\text { profissionais de } \\
\text { saúde }\end{array}$ & $\begin{array}{l}\text { Identificar obstáculos } \\
\text { para a inserção de pro- } \\
\text { gramas assistenciais } \\
\text { voltados para o público } \\
\text { masculino na atenção } \\
\text { primária à saúde. }\end{array}$ & $\begin{array}{l}\text { Os dados foram coletados entre } \\
\text { julho e agosto de } 2011 \text {, por meio } \\
\text { de entrevista semiestruturada. } \\
\text { Os depoimentos foram trabalha- } \\
\text { dos de acordo com a análise da } \\
\text { enunciação, proposta por Bardin. } \\
\text { Público estudado: Homem }\end{array}$ & $\begin{array}{l}\text { Os resultados revelaram como } \\
\text { principais entraves para inserção de } \\
\text { programas assistenciais voltados } \\
\text { para os homens as concepções de } \\
\text { gênero arraigadas socialmente, } \\
\text { bem como o modo de organização } \\
\text { dos serviços de atenção primária. }\end{array}$ \\
\hline $\begin{array}{l}\text { SOLANO et al, } \\
\text { 2017. J. Res.: } \\
\text { Fundam. Care. } \\
\text { Online }\end{array}$ & $\begin{array}{l}\text { O acesso do } \\
\text { homem ao } \\
\text { serviço de saúde } \\
\text { na atenção } \\
\text { primária }^{15}\end{array}$ & $\begin{array}{l}\text { Investigar os aspectos } \\
\text { que influenciam no } \\
\text { acesso do homem ao } \\
\text { serviço de saúde da } \\
\text { atenção primária. }\end{array}$ & $\begin{array}{c}\text { Trata-se de um estudo explora- } \\
\text { tório descritivo, com abordagem } \\
\text { qualitativa, realizado com oito } \\
\text { homens através de grupo focal } \\
\text { em outubro de } 2010 \text {. Os dados } \\
\text { foram analisados com base na } \\
\text { técnica do Discurso de Sujei- } \\
\text { to Coletivo Público estudado: } \\
\text { Homem }\end{array}$ & $\begin{array}{l}\text { Os usuários expressaram pou- } \\
\text { co investimento na organização } \\
\text { do serviço numa perspectiva de } \\
\text { gênero reforçando o senso-comum } \\
\text { de que os homens não são usuários } \\
\text { da atenção primária, tendo ainda } \\
\text { uma ideologia subsidiado pelo } \\
\text { patriarcado. }\end{array}$ \\
\hline $\begin{array}{l}\text { POZZATI et } \\
\text { al, 2013. Rev. } \\
\text { Enferm. UERJ }\end{array}$ & $\begin{array}{l}\text { O cuidado na } \\
\text { saúde dos ho- } \\
\text { mens: realidade } \\
\text { e perspectivas }{ }^{16}\end{array}$ & $\begin{array}{l}\text { Conhecer a produção } \\
\text { científica acerca do } \\
\text { cuidado à saúde dos } \\
\text { homens. }\end{array}$ & $\begin{array}{l}\text { Realizada uma revisão de litera- } \\
\text { tura na base de dados Literatura } \\
\text { Latino-Americana e Caribe em } \\
\text { Ciências da Saúde e Scientific } \\
\text { Electronic Library Online, no perí- } \\
\text { odo de } 1994 \text { a } 2011 \text {, utilizando a } \\
\text { palavra saúde do homem. Foram } \\
\text { selecionados } 15 \text { artigos, os quais } \\
\text { foram analisados pelo método } \\
\text { de análise de conteúdo Público } \\
\text { estudado: Homem }\end{array}$ & $\begin{array}{l}\text { Emergindo as categorias: a questão } \\
\text { de gênero e sua relação com o (des) } \\
\text { cuidado da saúde dos homens; } \\
\text { o retrato dos serviços no aten- } \\
\text { dimento à saúde dos homens; e } \\
\text { as estratégias necessárias para o } \\
\text { atendimento da saúde dos homens }\end{array}$ \\
\hline $\begin{array}{l}\text { BERTOLINI, SI- } \\
\text { MONETII, } 2014 . \\
\text { Escola Anna } \\
\text { Nery Revista de } \\
\text { Enfermagem }\end{array}$ & $\begin{array}{l}\text { O gênero } \\
\text { masculino e os } \\
\text { cuidados de saú- } \\
\text { de: a experiência } \\
\text { de homens de } \\
\text { um centro de } \\
\text { saúde }^{17}\end{array}$ & $\begin{array}{l}\text { Compreender como os } \\
\text { homens de um Centro } \\
\text { de Saúde se compor- } \\
\text { tam quanto aos cuida- } \\
\text { dos com a saúde. }\end{array}$ & $\begin{array}{l}\text { Estudo qualitativo, realizado em } \\
\text { um Centro de Saúde Escola que } \\
\text { selecionou por conveniência e } \\
\text { entrevistou } 15 \text { indivíduos do } \\
\text { gênero masculino, adultos e } \\
\text { organizou os dados conforme } \\
\text { o Discurso do Sujeito Coletivo. } \\
\text { Público estudado: Homem }\end{array}$ & $\begin{array}{l}\text { Emergiram quatro ideias centrais } \\
\text { que retratam os motivos para } \\
\text { procurar o serviço, problemas de } \\
\text { saúde, atitudes diante desses } \\
\text { problemas e participação nas ativi- } \\
\text { dades da unidade. Esses indivíduos } \\
\text { são assíduos, se preocupam em } \\
\text { seguir as recomendações recebidas } \\
\text { e utilizam o atendimento individual, } \\
\text { preferencialmente, por falta de } \\
\text { tempo, mas demonstram interesse } \\
\text { em participar de atividades em } \\
\text { grupo. }\end{array}$ \\
\hline $\begin{array}{l}\text { ALBUQUERQUE } \\
\text { et al, } 2014 . \\
\text { Escola Anna } \\
\text { Nery Revista de } \\
\text { Enfermagem }\end{array}$ & $\begin{array}{l}\text { O homem na } \\
\text { atenção básica: } \\
\text { percepções de } \\
\text { enfermeiros } \\
\text { sobre as implica- } \\
\text { ções do gênero } \\
\text { na saúde }{ }^{18}\end{array}$ & $\begin{array}{l}\text { Compreender a per- } \\
\text { cepção de enfermeiros } \\
\text { sobre as implicações } \\
\text { das questões de gêne- } \\
\text { ro na saúde do homem } \\
\text { e na oferta de serviços } \\
\text { a este público. }\end{array}$ & $\begin{array}{c}\text { Pesquisa qualitativa, realizada } \\
\text { com } 10 \text { enfermeiros inseridos } \\
\text { na Atenção Básica do municí- } \\
\text { pio de Juazeiro do Norte - CE, } \\
\text { através da adoção de entrevistas } \\
\text { semiestruturadas. Os discursos } \\
\text { obtidos foram categorizados e } \\
\text { analisados por meio da literatura } \\
\text { pertinente. Público estudado: } \\
\text { Homem }\end{array}$ & $\begin{array}{l}\text { Segundo percepção dos enfer- } \\
\text { meiros, existe pouca demanda do } \\
\text { segmento masculino aos servi- } \\
\text { ços de saúde, em decorrência da } \\
\text { socializaçã̃o do gênero e do déficit } \\
\text { na organização dos serviços, com } \\
\text { baixa qualificação profissional, já } \\
\text { que ressaltam não terem recebido } \\
\text { capacitações. }\end{array}$ \\
\hline
\end{tabular}




\begin{tabular}{|c|c|c|c|c|}
\hline $\begin{array}{c}\text { SEPARAVICH } \\
\text { CANESQU, } 2013 . \\
\text { Saúde Soc. São } \\
\text { Paulo }\end{array}$ & $\begin{array}{l}\text { Saúde do ho- } \\
\text { mem e mas- } \\
\text { culinidades na } \\
\text { Política Nacional } \\
\text { de Atenção } \\
\text { Integral à Saúde } \\
\text { do Homem: uma } \\
\text { revisão biblio- } \\
\text { gráfica }^{19}\end{array}$ & $\begin{array}{l}\text { Análise da saúde do } \\
\text { homem e masculinida- } \\
\text { des na PNAISH. }\end{array}$ & $\begin{array}{l}\text { revisa os textos que trataram } \\
\text { do tema nos periódicos de } \\
\text { Saúde Coletiva/Saúde Pública } \\
\text { no período de 2005-2011. Os } \\
\text { eixos temáticos encontrados } \\
\text { coincidem com as prioridades } \\
\text { conferidas pela Política Nacional } \\
\text { de Atenção Integral à Saúde do } \\
\text { Homem, criada pelo Ministério } \\
\text { da Saúde em 2008. Público estu- } \\
\text { dado: Homem }\end{array}$ & $\begin{array}{l}\text { o acesso dos homens aos serviços } \\
\text { de saúde, sexualidade, saúde re- } \\
\text { produtiva, violência e os principais } \\
\text { agravos à saúde masculina, contex- } \\
\text { tualizados au luz dos determinantes } \\
\text { sociais da saúde. Tais determinan- } \\
\text { tes se baseiam em um tipo de mas- } \\
\text { culinidade tradicional concebida } \\
\text { como hegemônica, que apesar de } \\
\text { comprometer a saúde masculina, } \\
\text { não é o tipo único de masculinidade } \\
\text { existente na sociedade. }\end{array}$ \\
\hline $\begin{array}{l}\text { RIBEIRO et } \\
\text { al, 2014. Rev. } \\
\text { Enferm. UERJ }\end{array}$ & $\begin{array}{l}\text { Saúde dos } \\
\text { homens: } \\
\text { abordagem na } \\
\text { formaçãa de } \\
\text { enfermeiros }\end{array}$ & $\begin{array}{c}\text { Analisar como a } \\
\text { temática relacionada } \\
\text { à saúde dos homens é } \\
\text { abordada nos currícu- } \\
\text { los dos Cursos de Gra- } \\
\text { duação em Enferma- } \\
\text { gem em um município } \\
\text { do Rio Grande do Sul } \\
\text { - RS, Brasil. }\end{array}$ & $\begin{array}{c}\text { Trata-se de uma pesquisa do- } \\
\text { cumental, quali-tativa, realizada } \\
\text { em três Cursos de Graduação } \\
\text { em Enfermagem, no período de } \\
\text { setembro a novembro de } 2010 . \\
\text { Utilizou-se a análise de conteúdo } \\
\text { temática. Público estudado: } \\
\text { Homem }\end{array}$ & $\begin{array}{l}\text { Os resultados mostraram uma } \\
\text { abordagem generalizada em } \\
\text { relação a saúde dos homens e a } \\
\text { inserção da Política Nacional de } \\
\text { Atenção Integral à Saúde do Ho- } \\
\text { mem nas discussões acadêmicas } \\
\text { da graduação em enfermagem. }\end{array}$ \\
\hline $\begin{array}{l}\text { SANTOS et al, } \\
\text { 2017. Rev. APS. }\end{array}$ & $\begin{array}{c}\text { Saúde dos } \\
\text { homens nas } \\
\text { percepções de } \\
\text { enfermeiros da } \\
\text { estratégia saúde } \\
\text { da família²1 }\end{array}$ & $\begin{array}{c}\text { Analisar as percep- } \\
\text { ções de enfermeiras } \\
\text { da Estratégia Saúde } \\
\text { da Familia sobre a } \\
\text { produção de cuidados } \\
\text { à saúde do homem. }\end{array}$ & $\begin{array}{l}\text { Trata-se de um estudo de abor- } \\
\text { dagem qualitativa, do tipo explo- } \\
\text { ratório e descritivo, cujo objetivo } \\
\text { foi analisar as percepções de } \\
\text { enfermeiras da Estratégia Saúde } \\
\text { da Familia sobre a produção de } \\
\text { cuidados à saúde do homem. } \\
\text { A análise dos dados se deu por } \\
\text { meio da Análise de Conteúdo } \\
\text { Temática. Público estudado: } \\
\text { Homem }\end{array}$ & $\begin{array}{c}\text { Os resultados apontaram para as } \\
\text { fragilidades que o público mascu- } \\
\text { lino se depara em relação aos ser- } \\
\text { viços de saúde da familia, eviden- } \\
\text { ciadas pela falta de estrutura dos } \\
\text { serviços; a falta de qualificação pro- } \\
\text { fissional para produção de cuidados } \\
\text { dirigidos ao público masculino e os } \\
\text { estereótipos de masculinidade que } \\
\text { afastam os homens dos serviços } \\
\text { de saúde. }\end{array}$ \\
\hline
\end{tabular}

\section{Feições construtivas da masculinidade}

A sociedade exerce um papel importante na modelagem de tendências, e nesse sentindo enquadra-se o ser homem, um ser humano constituído de princípios e doutrinas sociais de caráter comportamental, onde o posiciona como invulnerável, eximindo-o do ato de chorar e expor sentimentos como medo e ansiedade, culminando em uma construção sociocultural de condutas negativas ao seu processo de saúde doençą ${ }^{13}$.

Dentro da perspectiva social, a denominação do ser homem, corresponde a uma construção histórica e cultural ao qual transforma-se dentro de espaços culturais vivenciados ao longo de sua vida. Esses espaços possuem uma relevância na produtividade de conceitos transformadores dos valores sociais atribuídos a masculinidade ${ }^{19}$.

Diversos são os papeis sociais que com- põem o homem no processo de construção de sua masculinidade, dentre eles destacam: o líder, o protetor e o provedor. Em todos, o trabalho exerce uma função social, que foi construída ao longo da existência do homem, ao qual enriquece-os de maneira a envaidecer-se, uma vez que reconhecidos como trabalhadores atribuía-se a este o status de agente provedor da família, rotulando-o com a marca do ser masculino, herança da formação patriarcal ${ }^{17,15}$.

O homem desde os tempos remotos, traz uma carga do patriarcado, visível pelas cicatrizes deixadas em si de uma socialização onde o cuidado não é uma prática masculina, fazendo com que ecloda tabus no que diz respeito as mudanças. A contemporaneidade exige, portanto, que essa ideologia até então imperada, seja transposta, aponto de dá margem a uma nova forma de repensar novas bases paradigmáticas, de forma que em um futuro muito próximo, o homem passe a assumir uma postura diferenciada, levando ao desmonte de uma masculinidade tóxica ${ }^{15}$.

A partir das novas concepções dialogadas sobre gênero, iniciou-se um embate dos novos modelos de masculinidade, onde partindo da discussão do feminismo, o homem passa a obter visualização e destaca-se por questões opositoras, permeando por dentre os reflexos socialistas a respeito do ser homem. Nesse sentido, a ideia de invulnerabilidade imposta no processo de socialização juntamente com a as questões de gênero, passam a refletir de maneira negativa na necessidade do autocuidado do homem ${ }^{14}$.

$\mathrm{O}$ autocuidado do homem, influenciado pelas questôes de gênero intervêm nos hábitos diários produzindo estilo de vida 
que por muitas vezes são agentes de doenças e até morte. Assim, homens convictos de uma masculinidade socialmente construída, ricos em suas convicções e crenças acerca do ser homem, possuem uma ampla probabilidade de adoecerem, visto o contrassenso ao cuidar que ainda é visto como sendo exclusividade feminino ${ }^{19}$.

A necessidade em que os homens têm de se esmerarem no autocuidado, quase sempre é eclipsada pela construção patriarcal que esse sujeito, no decorrer das décadas sofreu. Essa formação é carregada de obrigatoriedades e ao mesmo tempo um decreto pelo qual esses comportamentos serão perpetuados, as atitudes provenientes desse modelo de homem, refletem no desconhecimento de si, do seu corpo, bem como, do cuidado à saúde ${ }^{19}$.

\section{Fatores impeditivos para a descons- trução da masculinidade em benefício do autocuidado}

Por muito tempo, a saúde do homem era abordada de forma leviana e fragmentada, bastante diferente das mulheres, e mediante a concepção de gênero, eram estereotipados como o modelo do ser humano inatingível. Entretanto, visto a transgressões à masculinidade imposta pela guerra dos sexos e movimentos feministas, a saúde do homem, de forma antagonista ao sucesso esperado, passa a ganhar visibilidade e nesse contexto os homens ainda que dotados de masculinidade, passam a reconhecer suas necessidades ${ }^{20-21}$.

O homem influenciado pela desigualdade de gênero sofre e é culpado pelos danos causados a sua própria saúde, implicando em multi contextos que impactam diretamente em sua vida. Desta forma, o homem tende a não adotar hábitos saudáveis, buscando apenas o serviço de saúde em situação de doença manifesta, de forma a valorizar as práticas curativas e desconhecendo a importância das ações preventivas ${ }^{15,18}$.

Estudos a respeito da construção de gênero, enriquecido pela representatividade feminina na contemporaneidade, robustece a não desigualdade entre homens e mulheres quando o assunto é saúde, promovendo uma mudança progressiva e sig- nificativa das atitudes dos homens em relação às demandas por serviços de saúde ${ }^{18}$.

Um movimento realizado entre atores coletivos de diversos setores da sociedade civil, cientifica, acadêmica e internacional, serviu como base para elaboração de um documento que aponta os danos sofridos pelos homens como sendo um problema de Saúde Pública e destaca a necessidade de mudança não somente na sua saúde, mas também de seus familiares. Frente a esse contexto de visibilidade o Ministério da Saúde (MS) concretiza a Política Nacional de Atenção Integral à Saúde do Homem (PNAISH), objetivando organizar, inserir, classificar e humanizar a atenção integrada à saúde do homem, promovendo a melhoria e contribuindo para redução do índice de mortalidade ${ }^{12,16,19-20}$.

Embora a PNAISH busque promover a melhoria das condições de saúde da população masculina, e procure contribuir significativamente na qualidade e aumento na expectativa de vida do homem, ainda há fatores impeditivos dentro do contexto sociocultural, político e econômico que de forma determinante reduz a adesão masculina aos serviços de saúde ${ }^{16,19}$.

Uma pesquisa realizada entre os meses de maio e agosto de 2013 em uma Unidades Integradas de Saúde (UIS) dos Distritos Sanitários do Município de João Pessoa na Paraíba, buscou por meio de relatos dos enfermeiros, identificar os problemas para a inclusão do homem nos serviços de saúde no nível primário. Revelou-se assim, um grande campo de dificuldades sendo traduzidas em três aspectos: o próprio homem; os profissionais e os serviços de atenção primária. $\mathrm{O}$ estudo mostrou que os homens não reconhecem a necessidade do âmbito preventivo à sua própria saúde, além da dificuldade que o modelo hegemônico da masculinidade exerce sobre sua postura, tanto no sentido que transcende a invulnerabilidade quanto no papel de provedor, pois o mundo do trabalho nas concepções socialmente androcêntricas, tende a expor ridicularizando-o durante o processo do autocuidado ${ }^{13}$.

Assim como o autor supracitado, alguns outros estudos apontam os profissionais e os serviços de saúde primária, como fatores responsáveis pelas dificuldades de inserção do homem na saúde. Déficit na capacitação técnico cientifica para a prática da PNAISH, pois ações educacionais na saúde do homem, que influenciem na construção de identidade e no processo de saúde-doença, são raras. $\mathrm{O}$ que se explica pelo espelho dos conceitos socialmente estabelecidos a respeito do que é ser homem em que os profissionais de saúde, entrelaçados em conjunturas socioculturais e atrelados a não capacitação, permitem interferência na prática assistencial ${ }^{12-13,15-18,20-21}$

Outro aspecto marcante que faz com que ecloda uma percepção não favorável para a criação do vínculo desse homem com a unidade, é a questão estrutural conciliado a feminilização do espaço. $\mathrm{O}$ fato dessa estrutura está preparada para o acolhimento do público materno infantil, da criança, do idoso por exemplo, e pelo fato desse ambiente deixar claro o público ao qual espera-se, bem como a composição enquanto equipe que na maioria das vezes é composta por mulheres, leva esse sujeito a fazer alusão de que esse formato de receptividade não condiz o que ele busca. Infere-se, portanto, que esse modelo de acolhimento significa um nó, nesse processo de identificação do homem ao meio ${ }^{12-14,18}$.

Assim, essa forma de acolhimento ao homem no serviço de saúde, precisa ser repensada para que não seja excludente e sim, que com medidas simples possa ser convidativa de maneira que o mesmo sinta-se incluso, levando o mesmo a crer que a assistência que ele precisa emane dessa equipe de profissionais da unidade de saúde.

\section{Assistência de enfermagem na saúde do homem}

É perceptível a inclusão do "homem e saúde" nas discussões de vários pesquisadores, sobretudo dos profissionais da área da saúde, com o objetivo de se criar estratégias para tratar das peculiaridades do homem para que haja a redução o máximo possível dos indicadores de morbimortalidade que delineia a saúde dos homens, começando essa intervenção pela atenção básica ${ }^{13}$.

É uma realidade que o homem se distancia das unidades básicas de saúde pois não dão 
atenção a promoção e prevenção da saúde, por esse motivo, cabe as unidades desenvolverem, ainda nesse nível de atenção meios pelos quais esse homem se encontre. Não existe a possibilidade de inserção desse homem nas rotinas das respectivas unidades, sem articulação junto à comunidade adstrita, agentes de saúde, enfermeiros, sendo esta uma demanda para a equipe como um todo ${ }^{13}$.

Para que a assistência possa abarcar todas as necessidades dos homens, parte-se portanto, de uma formação adequada com intuito de qualificar o profissional. É na formação acadêmica que se encontra o momento ideal para que esse profissional seja onusto de conhecimentos, até então negligenciados, para que possa lhe dá com a problemática da situação de saúde do homem. Quando passar a ser obrigatório o conteúdo voltado para a saúde do homem na grade curricular, logo, será visível os reflexos desse investimento direcionado a formação ${ }^{21}$.

A implantação da metodologia voltada para o público masculino possibilitará que os acadêmicos assumam uma visão holística das peculiaridades desse membro da população pouco visto nos seus aspectos de saúde. É preciso que a sociedade acadêmica veja, as questões de saúde pertinentes ao homem, como um tema transversal, e que a questão de gênero deve perpassar por todo o processo educacional permanente, assim, os profissionais de saúde terá que se debruçar sobre tais conteúdo ${ }^{20}$.

Á atenção ao homem, exige da equipe criatividade na abordagem de sua demanda. Utilizando instrumentos de aperfeiçoamento com base na educação continuada da equipe, fornecendo aos profissionais embasamento para mudança de postura, que por sua, exige empenho para além da técnica. É necessário a obtenção de uma visão ampla das necessidades expandindo os sentidos no que concerne à saúde do homem, desde questões biológicas até questões socioambientais, psicossociais e culturais. Desta forma, abastados de conhecimentos, terão condições de elaborarem medidas efetivas para abarcar todas as expectativas desse homem, atraindo-o para a assistência movido pela capacidade desses profissionais em atender as suas queixas como um todo ${ }^{14}$.
Para melhorar os índices que concerne a saúde dos homens, o profissional enfermeiro tem ao seu alcance chances de elaborar juntamente com sua equipe, meios pelos quais esse sujeito será visto na sua integralidade. $\mathrm{O}$ trabalho dessa equipe é trazer esse ator para compor o cenário da unidade básica de saúde e envolve-lo, fazendo com que ele se sinta parte integrante da assistência prestada, tornando a política com um caráter mais includente na atenção à saúde do homem ${ }^{19}$.

O impasse para a assistência ao homem, está relacionado a questão de horário, pois o expediente da equipe não condiz com a carga horária da clientela masculina. Sendo, portanto, uma das razões exposto por esses homens de se distanciarem cada vez mais das unidades. Por essa razão é de suma importância que haja uma mudança no processo de trabalho, afim de assistir essa população, estabelecendo uma assistência inclusiva. É necessário que os profissionais encarem a proposta saúde do homem, como sendo um acontecimento de rotina, e não, como um evento que será oferecido em datas esporádicas. Assim, abre-se precedentes para que o mesmo veja uma valorização por parte desse serviço ${ }^{12}$.

Uma estratégia que pode facilitar a captação desse homem pela unidade de saúde, é a desconstrução na conformação das equipes que ali estão para assistir esse sujeito, carregado de dogmas. $\mathrm{O}$ fato das equipes serem formadas em sua grande maioria por mulheres, cria-se aí, um impasse, pois esse homem não se sente à vontade em um ambiente composto por mulheres tanto do ponto de vista clientes, como também, compondo a equipe. Ter nessa conjuntura outros homens, sendo agentes do cuidado, permite que o público masculino se encontre nessa assistência. Tornando-os reconhecidos e acolhidos em suas demandas. $\mathrm{O}$ ponto chave para a permanência desse individuo carente de cuidado, é sentir-se pertencente este ambiente ${ }^{14,19}$.

Fazer com que o homem entenda que a unidade saúde primária é um espaço masculino é preciso que a equipe se esmere em cativar esse sujeito de alguma forma. Uma maneira de se constituir vínculo com o pú- blico masculino é realizar ações pontuais referente a sua demanda, consultas e esclarecimento acerca das doenças prevalentes nesse público, atividades na comunidade, experiências durante o campeonato de futebol, oficinas e discussões na sala de espera com temas que interessem ao público masculino. Dessa forma a equipe possibilita que caia por terra a ideia contorcida que ele tem da unidade de ser feminina. Portanto, a atenção voltada para a saúde do homem não é estabelecida através de uma receita pronta e acabada, uma vez que essa questão exige uma certa expertise por parte da equipe de que cada comunidade/usuário possui necessidades distintas ${ }^{14}$.

\section{CONCLUSÃO}

É notável um resquício de um passado que deixou marcas por sua intransigência no que diz respeito a postura do verdadeiro homem, onde percebe-se que a influência heterocêntrica ainda impera e coloca o homem em uma condição de risco contínuo. As estatísticas mostram o quanto a herança deixada por tempos remotos de uma formação de masculinidade tóxica, tem contribuído para o adoecimento, morte e interferências graves nas famílias, visto que este homem não tem coragem o suficiente para transcender de uma postura de demonstração exagerada de força, para uma de demonstração de afeto e sensibilidade, passando assim a negligenciar a sua saúde em todos os aspectos.

O fato da representatividade de uma masculinidade hegemônica, nos cenários que tem um certo destaque, tem tido influência direta na formação do sujeito, bem como a formação da personalidade de meninos e homens de uma sociedade que carece de um novo formato de homem, este homem fruto dessa influência é danoso para com ele e também para a família e coletividade.

É necessário o fortalecimento do ensino técnico científico nas academias, para a preparação dos futuros profissionais, dos gestores em fazer com que a política voltada para o público masculino seja implantada, das equipes em criar estratégia para acolher de forma integral esse homem. 


\section{REFERÊNCIAS}

1. Brasiliense D, Ansel P. Representações da masculinidade viril contemporânea no programa popular da Rádio Cidade FM: Hora dos Perdidos. RECIIS - Rev Eletron Comun Inf Inov Saúde [periódico na Internet]. 2016 [acessado 2020 Nov 20].; 10 (2). Disponivel em: https:/www.reciis.icict. fiocruz.br/index.php/reciis/article/view/1123/pdf1123

2. Gaspodini IB, Canabarro RP, Cenci CMB, Perrone CM. Masculinidades em diálogo: Produção de sentido a partir de marcadores sociais da diferença. Mudanças - Psicologia da Saúde [periódico na Internet]. 2017 [acessado 2020 Nov 20]; 25 (1):17-25. Disponivel em:https:/www. metodista.br/revistas/revistas-metodista/index.php/MUD/article/ view/7101/5708

3. Leite JF, Paiva R, Amorim AKM, Dimenstein M, Carvalho L, França A. Sentidos da Saúde numa Perspectiva de Gênero: um Estudo com Homens da Cidade de Natal/RN. Psicologia: Ciência e Profissão [periódico na Internet]. 2016 [acessado 2020 Nov 2036(2): 341-53. Disponivel em: https:/www.scielo.br/pdf/pcp/v36n2/1982-3703-pcp-36-2-0341.pdf

4. Teixeira DB. Atenção à saúde do homem: análise da sua resistência na procura dos serviços de saúde. Rev Cubana Enferm [periódico na Internet]. 2016 [acessado 2020 dez 15]; 32(4). Disponível em http://www. revenfermeria.sld.cu/index.php/enf/article/view/985

5. Oliveira MM, Daher DV, Silva JLL, Andrade SSCA. A saúde do homem em questão: busca por atendimento na atenção básica de saúde. Ciência \& Saúde Coletiva [periódico na Internet]. 2015 [acessado 2020 Nov 20]; 20(1): 273-278. Disponivel em: https:/www.scielo.br/scielo. php?script=sci_arttext\&pid=S1413-81232015000100273

6. Prodanov CC, Freitas EC. Metodologia do trabalho científico: métodos e técnicas da pesquisa e do trabalho acadêmico. 2. ed. Novo Hamburgo: Feevale, 2013 [acessado 2020 Nov 20]. Disponível em: https:/www.feevale.br/institucional/editora-feevale/metodologia-do-trabalho-cientifico---2-edicao

7. Ogrinc G, Davies L, Goodman D, Batalden P, Davidoff F, Stevens D. SQUIRE 2.0 (Standards for QUality Improvement Reporting Excellence): revised publication guidelines from a detailed consensus process: Table 1. BMJ Qual Saf. 2016; 25(12): 986-92. Doi: 10.1136/bmjqs-2015-004411

8. Liberati A, Altman DG, Tetzlaff J, Mulrow C, Gotzsche PC, loannidis JPA etal. The PRISMA Statement for Reporting Systematic Reviews and Meta-Analyses of Studies That Evaluate Health Care Interventions: Explanation and Elaboration. Res Mehods Reportingehods Report [Serial on the Internet]. 6(7):e1000100; 2009 [acessado 2020 dez 15]. Disponível em: https:/www.bmj.com/content/339/bmj.b2700

9. Moher D, Liberati A, Tetzlaff J, Altman DG. PRISMA Group. Preferred reporting items for systematic reviews and meta-analyses: the PRISMA Statement. Ann Intern Med [Serial on the Internet]. 3(3): 123-30; 2009 [acessado 2020 dez 15]. Available from: https:/pubmed.ncbi.nlm.nih. gov/19622511/

10. Bardin L. Análise de Conteúdo. 5ª ed. Lisboa/Portugal: Edições 70, 2011.

11. Sippert L. Análise da estrutura temática em resenhas de alunos do Ensino Superior numa perspectiva da Linguística Sistêmico-Funcional. D.E.L.T.A., 2018, 34 (1):113-47.

12. Cordeiro SVL, Fontes WD, Fonsêca RLS, Barboza TM, Cordeiro
CA. Atenção básica à saúde masculina: possibilidades e limites no atendimento noturno. Escola Anna Nery Revista de Enfermagem [periódico na Internet]. 2014 [acessado 2020 dez 15]; 18(4): 644-9. Disponivel em: https:/www.scielo.br/scielo.php?script=sci_arttext\&pid=S1414-81452014000400644

13. Moreira RLSF, Fontes WD, Barboza TM. Dificuldades de inserção do homem na atenção básica a saúde: a fala dos enfermeiros. Escola Anna Nery Revista de Enfermagem. [periódico na Internet]. 2014 [ acessado 2020 dez 15 18(4): 615-21. Disponivel em: https:/www.scielo.br/ scielo.php?script=sci_arttext\&pid=\$1414-81452014000400615\&l$\mathrm{ng}=\mathrm{en} \& \mathrm{nrm}=$ iso\&tlng=pt

14. Brito RS, SantosDLAS. Entraves para Implementação de Programas Assistenciais Dirigidos ao Público Masculino: Visão de Profissionais de Saúde. Rev. Enferm. UERJ, [periódico na Internet]. 2013 [acessado 2020 dez 15]; 21(esp.1): 654-9. Disponivel em: https:/www.e-publicacoes. uerj.br/index.php/enfermagemuerj/article/view/10044/8072

15. Solano LC, Bezerra MAC, Medeiros RS, Carlos EF, Carvalho FPB, Miranda FAN. O Acesso do Homem ao Serviço de Saúde na Atenção Primária. J. Res.: Fundam. Care. Online [periódico na Internet]. 2017 [acessado 2020 Nov 20]; 9(2): 302-08. Disponivel em: http:/www.seer. unirio.br/index.php/cuidadofundamental/article/view/3270

16. Pozzati R, Beuter M, Rocha LS, Santos NOS, Budó MLD, Girardon-Perlini NMO. O Cuidado na Saúde dos Homens: Realidade e Perspectivas. Rev. Enferm. UERJ [periódico na Internet]. 2013 [acessado 2020 Nov 20]]; 21(4): 540-5. Disponível em: https:/www.e-publicacoes. uerj.br/index.php/enfermagemuerj/article/view/10032/7821

17. Bertolini DNP, Simonetti JP. O gênero masculino e os cuidados de saúde: a experiência de homens de um centro de saúde. Escola Anna Nery Revista de Enfermagem. [periódico na Internet]. 2014 [acessado 2020 dez 15; 18(4): 722-27. Disponível em: https:/www.scielo.br/ scielo.php?script=sci_arttext\&pid=S1414-81452014000400722\&l$\mathrm{ng}=\mathrm{en} \& \mathrm{nrm}=$ iso\&tlng=pt

18. Albuquerque GA, Leite MF, Belém JM, Nunes JFC, Oliveira MA, Adami F. O homem na atenção básica: percepções de enfermeiros sobre as implicações do gênero na saúde. Escola Anna Nery Revista de Enfermagem [periódico na Internet]. 2014 [acessado 2020 dez 15]; 18(4); 60714. Disponível em: https:/www.scielo.br/scielo.php?script=sci_arttext\&pid=S1414-81452014000400607

19. Separavich MA, Canesqui AM. Saúde do homem e masculinidades na Política Nacional de Atenção Integral à Saúde do Homem: uma revisão bibliográfica. Saúde Soc. [periódico na Internet]. 2013 [acessado 2020 Nov 20]]; 22(2): 415-28. Disponivel em: https:/www.scielo.br/scielo. php?script=sci_arttext\&pid=S0104-12902013000200013

20. Ribeiro DB, Terra MG, Lacchinni AJB, Camponogara S, Beuter M, Silva CT. Saúde dos homens: abordagem na formação de enfermeiros. Rev enferm UERJ [periódico na Internet]. 2014 [acessado 2020 dez 15]; 22(4):540-5. Disponível em: https:/www.e-publicacoes.uerj.br/index. php/enfermagemuerj/article/view/15398

21. Santos EM, Figueredo GA, Mafra ALS, Reis HFT, Louzado JA, Santos GM. Saúde dos Homens nas Percepções de Enfermeiros da Estratégia Saúde da Familia. Rev. APS. [periódico na Internet]. 2017 [acessado 2020 Nov 20]; 20(2):231-8. Disponível em: https:/periodicos.ufjf.br/index.php/ aps/article/view/16058 